\title{
Variation of parameters method for optimizing annular fins with variable thermal properties
}

\author{
Isıl parametreleri değişken olan dairesel kanatların parametrelerin \\ değişimi yöntemi kullanılarak optimizasyonu
}

\author{
Cihat ARSLANTÜRK ${ }^{*}$ iD \\ ${ }^{1}$ Mechanical Engineering Department, Engineering Faculty, Ataturk University, Erzurum, Turkey. \\ carslan@atauni.edu.tr
}

Received/Geliș Tarihi: 25.01.2016, Accepted/Kabul Tarihi: 11.05.2017

* Corresponding author/Yazışılan Yazar

doi: $10.5505 /$ pajes.2016.78736 Research Article/Araștırma Makalesi

\begin{abstract}
The aim of this study is to offer useful correlation equations to the designer for the optimum design of annular fins with thermal properties varying with temperature. In order to obtain the optimum size of the fins, the heat transfer from the fin must be calculated with the least assumptions possible. Therefore, the variation of the heat transfer coefficient and thermal conductivity with the temperature are considered in this study and a nonlinear fin equation is solved with the variation of parameters method, which is quite new in the solution of nonlinear heat transfer problems. Heat transfer rate from the fin to the environment is calculated in terms of dimensionless problem parameters with the help of the obtained temperature distribution. Fin geometries maximizing the heat transfer rate are determined for the given problem parameters. These results, which can be used for nucleate boiling, natural convection and forced convection heat transfer modes, are offered to the designer with two identical correlation equations.
\end{abstract}

Keywords: Annular fins, Optimization, Variable thermal conductivity, Nonlinear differential equations, Variable heat transfer coefficient, Variation of parameters method

\begin{abstract}
Öz
Bu çalışmanın amacı, ısıl özelliklerin sıcaklıkla değiştiği dairesel kanatların optimum tasarımı için, tasarımcıya kullanışlı korelasyon denklemleri sunmaktır. Kanatların optimum boyutlarını elde etmek için kanattan olan Isı transferinin mümkün olan en az kabulle hesaplanması gerekir. Bu nedenle, bu çalışmada ısı taşınım katsayısı ve ısıl iletkenliğin sıcaklıkla değișimi göz önüne alınmıș ve lineer olmayan kanat denklemi, nonlinear problemlerin çözümünde kullanımı çok yeni olan parametrelerin değişimi yöntemi ile çözülmüş, elde edilen sicaklık dağılımı yardımıyla kanattan çevreye olan ısı transfer hızı boyutsuz problem parametreleri cinsinden hesaplanmıștır. Verilen problem parametreleri için Isı transfer hızını maksimum yapan kanat geometrileri saptanmıştır. Kaynama, doğal taşınım ve zorlanmış tașınımla Isı transfer modları için kullanılabilecek bu sonuçlar iki eș korelasyon denklemi ile tasarımcının hizmetine sunulmuştur.
\end{abstract}

Anahtar kelimeler: Dairesel kanatlar, Optimizasyon, Doğrusa olmayan diferansiyel denklemler, Değișken ısıl iletkenlik, Değișken ısı taşınım katsayısı

\section{Introduction}

Finned surfaces are the thermal equipment used for increasing the heat transfer from a solid surface to the environment. An extensive review containing the research carried out on this subject is available in the literature [1]. Fins are used in many areas such as industrial ovens, aircraft and spacecraft radiators, cooling, heating and air conditioning processes, the chemical industry and for cooling electronic systems. The environments in which fins having various sizes and geometries are used have different flow fields and thus various heat transfer modes. Although thermal analysis of the fins is generally performed in terms of the constant heat transfer coefficient, in reality, heat transfer coefficients for different heat transfer modes are the functions of the temperature difference between the fins and the environment [2]. There are many studies in the literature considering the variation of the heat transfer coefficient [2]-[6]. Laor and Kalman [2] presented a therotical-numerical analysis of longitudinal and annular fins which subject to a temperaturedependent heat transfer coefficient. The thermal analysis of the annular rectangular profile fins with variable thermal properties is investigated by using the homotopy analysis method [3]. The Adomian decomposition method is used to analyze the thermal characteristics of a straight rectangular fin for all possible types of heat transfer [4]. In this study, the local heat transfer coefficient is assumed to vary with a power-law function of temperature. Kim and Huang [5] proposed a new series solution to the fin problem with temperature-dependent thermal conductivity and a temperature-dependent heat transfer coefficient. The homotopy analysis method is used to evaluate the analytical approximate solutions and efficiency of the nonlinear fin problem with temperature-dependent thermal conductivity and heat transfer coefficient [6]. In a different study, authors aim to use Least Square Method for obtaining the temperature distribution in longitudinal fins with temperature-dependent thermal parameters and different section shapes and heat generation [7].

Thermal conductivities of the materials used for manufacturing the fins are known to change with the temperature. In particular, in the cases where the temperature differences between the fins and the environment are high, the effect of this variation on the heat discharged from the fin is emphasized as significant. Many studies are available in the literature considering this variation [8]-[16]. The optimum design of an annular fin with temperature-dependent thermal conductivity is analyzed by Arslanturk [8]. In a study presented by Kundu and Bhanja [9], an exercise has been devoted to establish an analytical model for thermal performance and optimization of a constructal fin subject to variable thermal conductivity of fin material and convective heat transfer coefficient over the fin surface. The Least Square Method is introduced by Aziz and Bouaziz [10] for predicting the performance of longitudinal fins 
with variable thermal-conductivity. An analytical study based on the Adomian decomposition method on thermal performance and optimization for an absorber plate fin having variable thermal conductivity and overall loss coefficient has been conducted by Kundu [11]. A homotopy analysis method (HAM) is used to develop analytical solution for the thermal performance of a straight fin of trapezoidal profile when both the thermal conductivity and the heat transfer coefficient are temperature dependent [12]. Aziz and Khani [13] studied convection-radiation of a continuously moving fin of variable thermal conductivity. On the other hand, Torabi et al. [14] worked on same problem by using differential transformation method. Mosayebidorcheh et al. [15] studied the transient thermal analysis of longitudinal fins with variable cross section considering internal heat generation. In this study, it is assumed that both thermal conductivity and internal heat generation are as linear functions of temperature. Moradi et al. [16] investigated the convection and radiation effects in the analysis of performance of a porous triangular fin with temperaturedependent thermal conductivity.

Since many fins are used in a surface, achieving the desired heat transfer by using minimum fin material gains importance in terms of costs. In order to obtain the optimum sizes of the fins, the heat transfer from the fin must be calculated with the least assumption possible. Therefore, the variations of the heat transfer coefficient and the thermal conductivity must be considered.

In this study, the thermal analysis of annular fins with rectangular profile working in different heat transfer modes was conducted. Fin equation obtained as a result of the varying heat transfer coefficient and thermal conductivity is highly nonlinear. To obtain general results, fin equation is made dimensionless and dimensionless nonlinear fin equation containing dimensionless problem parameters is obtained. These mentioned parameters are defined as thermalconductivity parameter representing the thermal conductivity variation, fin parameter including thermal and geometric properties of the fin, exponential coefficient representing the heat transfer mode, the ratio of the dimensionless fin thickness and the fin radius. Dimensionless fin equation is solved with the variation of parameters method (VPM), which is a wellknown method frequently used for solving inhomogeneous linear differential equations [17]. However, it was proved recently that this method can be used effectively in the solution of nonlinear differential equations [18]-[20]. In 2010, MohyudDin et al. [18] applied VPM successfully in various initial and boundary nonlinear value problems. Rahmatullah and MohyudDin [19] solved nonlinear diffusion problems with this method. Recently, Moore [20] used this method in the solution of nonlinear direct and inverse heat transfer problems. Moore and Jones [21] analyzed a conduction-radiation problem in absorbing, and emitting non-gray planar media using this method. In order to test the accuracy and efficiency of the method, Moore compared the solution in the literature and the results obtained from this method proved that it gives accurate and precise results [20]. References [20] and [21] are the first studies in which VPM has been used in the solution of nonlinear heat transfer problems.

By using temperature distribution obtained from the solution of the nonlinear fin equation with VPM, heat transfer rate is expressed as a function of the problem parameters. At this stage, fin geometry maximizing the heat transfer rate for a given fin volume is obtained in a wide range of parameters.
Optimization results are expressed by the correlation equations that the user can easily use. These equations are thought to be important tools offered in the literature for the optimum design of annular fins working in boiling, natural convection and forced convection transfer modes.

\section{Mathematical model}

This study was conducted to analyze an annular fin of rectangular profile (Figure1). The base temperature of the fin and the ambient fluid temperature are $T_{b}$ and $T_{\infty}$, respectively. The fin has these dimensions: thickness $\mathrm{t}$, inner radius $r_{i}$ and outer radius $r_{o}$. Since the fin is assumed to be thin and the temperature gradient at the fin tip approaches zero, there is no heat transfer from the fin tip. It is assumed that the heat conduction is one-dimensional, that is, $T=T(r)$. The convection heat transfer coefficient and thermal conductivity of the fin are temperature dependent as mentioned below. Applying the first law of thermodynamics to the differential fin element of Figure 1, the fin equation is expressed as follows.

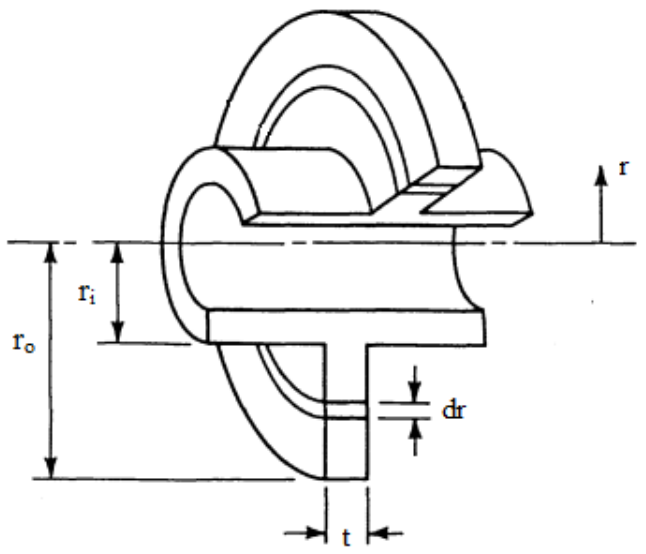

Figure 1: Geometry of an annular fin.

$$
\frac{1}{r} \frac{d}{d r}\left[k(T) r \frac{d T}{d r}\right]-h(T)\left(T-T_{\infty}\right)=0
$$

Thermal conductivity of the fin and the convection heat transfer coefficient are temperature dependent according to [3].

$$
\begin{aligned}
k(T) & =k_{\infty}\left[1+\kappa\left(T-T_{\infty}\right)\right] \\
h & =h_{b}\left[\frac{T-T_{\infty}}{T_{b}-T_{\infty}}\right]^{m}
\end{aligned}
$$

It is mentioned that the form of Eq. (3) is suitable for heat transfer coefficients in free convection, forced convection, nucleate boiling and space radiation at zero ambient temperature in the literature [2]-[5]. The various values of $\mathrm{m}$ correspond to different heat transfer modes: For free convection $m=1 / 3$ or $1 / 4$ for radiation $m=3$ and for boiling $m=1 / 3,2$ or 3 . For constant heat transfer coefficient, $m=0$ can be used.

In order to obtain the dimensionless formulation of the problem, it is defined the following dimensionless parameters.

$$
\begin{gathered}
R=\frac{r-r_{i}}{r_{i}}, \quad \theta=\frac{T-T_{\infty}}{T_{b}-T_{\infty}}, \quad B i=\frac{2 h_{b} r_{i}}{k_{\infty}} \\
\delta=\frac{t}{r_{i}}, \lambda=\frac{r_{o}}{r_{i}}, \psi=\frac{B i}{\delta}, \beta=\kappa\left(T-T_{\infty}\right)
\end{gathered}
$$


Where; $R$ dimensionless radial coordinate, $\theta$ dimensionless temperature, $B i$ Biot number, $\delta$ thickness-radius ratio, $\lambda$, radii ratio, $\psi$, thermo-geometric fin parameter, and $\beta$, a parameter describing the variation of thermal conductivity.

The governing differential equation and its boundary conditions can be written in non-dimensional form as:

$$
\frac{1}{1+R} \frac{d}{d R}\left[(1+R) \frac{d \theta}{d R}\right]=\frac{1}{1+\beta \theta}\left[\psi \theta^{m+1}-\beta\left(\frac{d \theta}{d R}\right)^{2}\right]
$$

With boundary conditions

$$
\begin{gathered}
\theta=1 \text { at } R=0 \\
\frac{d \theta}{d R}=0 \quad \text { at } R=\lambda-1
\end{gathered}
$$

\section{Variation of parameters method for nonlinear problems}

The method was first developed by Lagrange JL (1736-1813) for solving linear non- homogeneous differential equations [17]. It has been shown that the method can also be used to solve nonlinear differential equations [18]-[20].

Consider a nonlinear differential equation.

$$
\theta=f(R, \theta, \dot{\theta})
$$

Where, $\mathrm{L}$ is a second order linear operator.

The related homogeneous differential equation has two linear independent solutions and the complementary solution of the homogeneous equation can be expressed as,

$$
\theta_{c}(R)=c_{1} \theta_{c, 1}(R)+c_{2} \theta_{c, 2}(R)
$$

Where, $c_{1}$ and $c_{2}$ are constants and $\theta_{c, 1}$ and $\theta_{c, 2}$ form a fundamental set of solutions of the homogeneous equation. The basic idea behind the VPM is to seek a particular solution of the form

$$
\theta(R)=v_{1}(R) \theta_{c, 1}(R)+v_{2}(R) \theta_{c, 2}(R)
$$

The solution procedure is the same as for a linear differential equation such that [17].

$$
\begin{aligned}
\theta_{p}(R)=c_{1} \theta_{c, 1}(R) & +c_{2} \theta_{c, 2}(R)+v_{1}(R) \theta_{c, 1}(R) \\
& +v_{2}(R) \theta_{c, 2}(R)
\end{aligned}
$$

Where,

$$
\begin{aligned}
& v_{1}(R)=-\int_{0}^{R} \frac{f\left(R^{\prime}, \theta, \dot{\theta}\right) \theta_{c, 2}\left(R^{\prime}\right)}{W\left(\theta_{c, 1}\left(R^{\prime}\right), \theta_{c, 2}\left(R^{\prime}\right)\right)} d R^{\prime} \\
& v_{2}(R)=\int_{0}^{R} \frac{f\left(R^{\prime}, \theta, \dot{\theta}\right) \theta_{c, 1}\left(R^{\prime}\right)}{W\left(\theta_{c, 1}\left(R^{\prime}\right), \theta_{c, 2}\left(R^{\prime}\right)\right)} d R^{\prime}
\end{aligned}
$$

Where,

$$
W\left(\theta_{c, 1}, \theta_{c, 2}\right)=\left|\begin{array}{ll}
\theta_{c, 1} & \theta_{c, 2} \\
\dot{\theta}_{c, 1} & \dot{\theta}_{c, 2}
\end{array}\right|
$$

Because, $\theta$ appears on both sides Eq. (9), an iterative approach is required to solve $\theta$. Although not a closed-form solution because of the iteration required, the solution can still be considered exact if $f$ is only a function of $R$ and $\theta$ because the numerical integration required by Eqs. (10a) and (10b) can be performed to an arbitrary degree of accuracy. If $f$ is also a function of the derivatives of $\theta$, finite difference equations must be used to approximate these derivatives [20].

\section{The fin temperature distribution}

The homogeneous equation corresponding to the fin equation, i.e. Eq. (5a), is integrated twice, yielding the complementary solution.

$$
\theta_{c}(R)=c_{1} \theta_{c, 1}(R)+c_{2} \theta_{c, 2}(R)=c_{1} \ln (1+R)+c_{2}
$$

The particular solution can be written as according to Eq. (8).

$$
\theta_{p}(R)=v_{1}(\mathrm{R}) \ln (1+R)+v_{2}(R)
$$

The dimensionless temperature profile is the sum of the complementary and particular solutions.

$$
\theta(R)=c_{1}(\mathrm{R}) \ln (1+R)+c_{2}+v_{1}(\mathrm{R}) \ln (1+R)+v_{2}(R)
$$

The constants $c_{1}$ and $c_{2}$ in Eq.(14) are found by applying the boundary conditions given in Eqs. (5b) and (5c). By substituting the constants into Eq. (14), the temperature profile is obtained.

$$
\begin{aligned}
\theta(R) & =1-\ln (1+R) \int_{0}^{\lambda-1}(1+R) g(R, \theta, \dot{\theta}) d R \\
& +\ln (1+R) \int_{0}^{R}\left(1+R^{\prime}\right) g\left(R^{\prime}, \theta, \dot{\theta}\right) d R^{\prime} \\
& +\int_{0}^{R}\left(1+R^{\prime}\right) \ln \left(1+R^{\prime}\right) g\left(R^{\prime}, \theta, \dot{\theta}\right) d R^{\prime}
\end{aligned}
$$

Where

$$
g(R, \theta, \dot{\theta})=\frac{1}{(1+\beta \theta)}\left[\psi \theta^{m+1}-\beta \dot{\theta}^{2}\right]
$$

Because, $\theta$ and appears on both sides Eq. (15), an iterative approach is required to solve $\theta$. The iterative solution begins with an initial guess of the temperature profile. To calculate a new temperature profile, this guess is used to numerically integrate the integrals on the right side of Eq. (17).

$$
\begin{aligned}
\theta^{n+1} & =1-\ln (1+R) \int_{0}^{\lambda-1}(1+R) g\left(R, \theta^{n}, \dot{\theta}^{n}\right) d R \\
& +\ln (1+R) \int_{0}^{R}\left(1+R^{\prime}\right) g\left(R^{\prime}, \theta^{n}, \dot{\theta}^{n}\right) d R^{\prime} \\
& +\int_{0}^{R}\left(1+R^{\prime}\right) \ln \left(1+R^{\prime}\right) g\left(R^{\prime}, \theta^{n}, \dot{\theta}^{n}\right) d R^{\prime}
\end{aligned}
$$

In this study, the linear temperature profile is used as the initial guess. The finite difference method is used to express the derivatives of $\theta$ in Eq. (17). With the initial guess, a new temperature profile is updated using Eq. (17). This updated temperature profile is then used to recalculate a new temperature profile and repeated until convergence is obtained. Convergence is considered achieved when the Euclidean norm of the difference between the calculated temperature profile of the current iteration and that of the previous iteration reaches the tolerance which is specified as $10^{-6}$.

When $\beta$ equals to zero, the function $g$ describing in Eq. (16) does not include the derivative of $\theta$. Although the method requires an iterative approach and numerical integration, the solution to this special case can be considered exact because 
numerical integration can be performed to an arbitrary degree of precision [20]. For $\beta \neq 0$, the finite difference method must be used approximate the derivative of $\theta$ on the right hand side of Eq. (17). In this case the approximate solution of the problem is obtained.

\section{Optimization}

Steady-state heat transfer rate from the fin is calculated from the Fourier heat conduction law.

$$
\dot{Q}=\left[2 \pi r_{i} t k \frac{d T}{d r}\right]_{r=r_{i}}
$$

By using the dimensionless parameters, dimensionless heat transfer rates can be defined as follows.

$$
\dot{q}=\frac{\dot{Q}}{2 \pi r_{l} k_{\infty}\left(T_{b}-T_{\infty}\right)}=\delta(1+\beta)\left[\frac{d \theta}{d R}\right]_{R=0}
$$

Dimensional and dimensionless fin volumes are calculated as below.

$$
\begin{gathered}
V=\pi\left(r_{o}^{2}-r_{i}^{2}\right) t \\
v=\frac{V}{\pi r_{i}^{3}}=\left(\lambda^{2}-1\right) \delta
\end{gathered}
$$

In Eq. (21) $\delta$ is taken and rewritten into the Eq. (19) dimensionless heat transfer rate can be defined with the following function.

$$
\dot{q}=\dot{q}(m, v, \beta, \lambda, B i)
$$

For given $m, v$ and $\beta$ and $B i$, dimensionless heat transfer rate is only the function of $\lambda$, the radii ratio.

$$
\dot{q}=\dot{q}(\lambda)
$$

$\lambda$ value maximizing this function and the maximum heat transfer rate corresponding to this value are calculated by a classical search method.

\section{Results and discussion}

In this section, firstly the convergence and accuracy of the solution made with VPM is investigated. Eq. (17) must be solved iteratively in order to obtain temperature distribution. Three integrals in Eq. (17) are solved numerically with the trapezoidal rule. How fin tip temperature changes with the sub-region number is shown in Table 1. It can be seen from the table that the 100 sub-region is adequate in order to obtain the solution regardless of the number of the sub-region. Since fin equation for $(\beta ; m)=(0 ; 0)$ state, i.e., $\mathrm{Eq}(5 \mathrm{a})$ is linear, an exact analytical solution of the equation exists [22]. When Table 2 , in which the comparison of the exact solution and VPM are given for three different values of the fin parameters, is examined both solutions are seen to be perfectly compatible.

Moreover, this study and the results obtained by Aksoy [3] with the homotopy analysis method (HAM) are compared for the cases where the equation is nonlinear.

Figure 2 is drawn to make this comparison. This comparison performed for the $(\lambda ; \psi ; m)=(2.0 ; 0.25 ; 0.25)$ parameter group shows that the results from both methods are perfectly compatible.

In Figure 3, how heat transfer rate changes with the fin geometry is investigated for a given fin volume and Biot number, $(v ; B i)=(0.8 ; 0.01)$. When Figure 3 is investigated, it is understood that the heat transfer rate reaches the highest value in a $\lambda$ value and this $\lambda$ value corresponding to the maximum point varies with the thermal conductivity parameter $\beta$. From the figure, $\lambda$ value in which the highest heat transfer rate occurs shifts to the lower values with decreased $\beta$. Increases of the $m$ parameters defining the variation of the heat transfer coefficient with the temperature lead to a decrease in heat transfer rate. The coordinates of the maximum points of the curves in Figure 3 are determined with a search method explained in the previous section. Optimum radii ratio and the maximum heat transfer rate are shown in Figure 4 as a function of $B i$ for five different fin volumes.

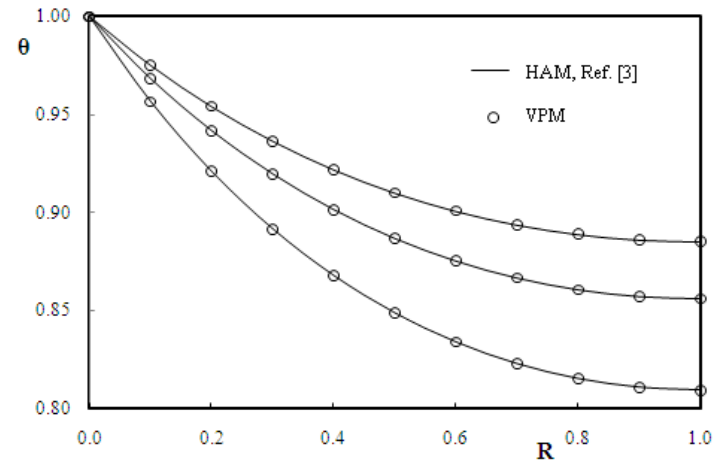

Figure 2: HAM (Ref. 3) and present VPM numerical results.

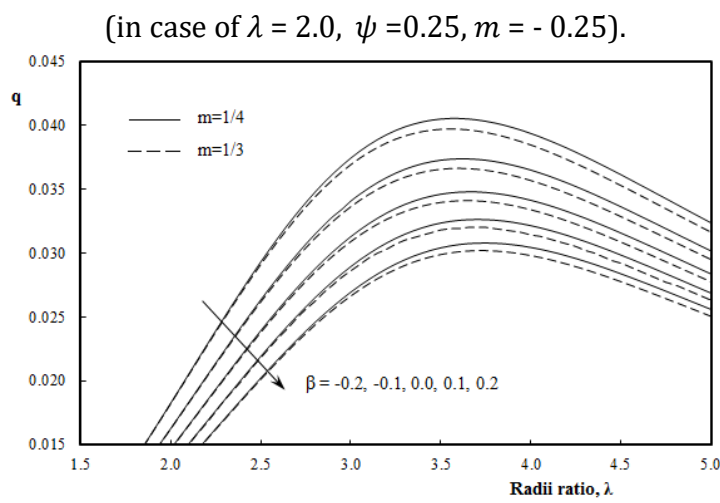

Figure 3: Heat transfer rate as a function of radii ratio $\lambda$, for

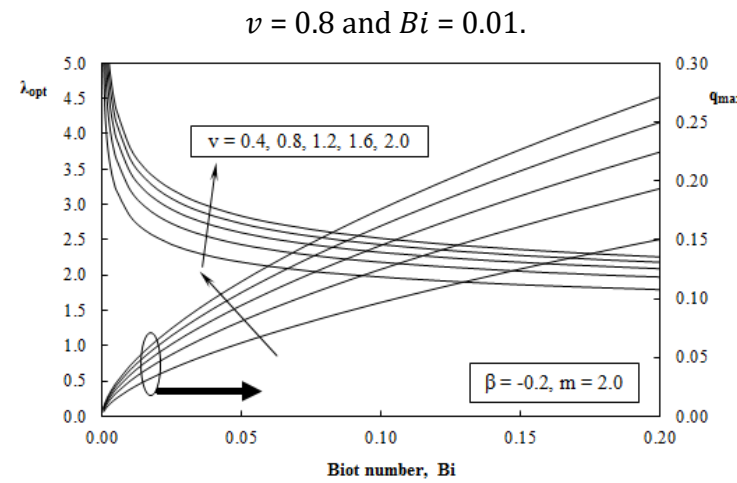

Figure 4: Optimal values of radii ratio and heat transfer rate as a function of $B i$ number for five different fin volumes.

Optimum radii ratio for a given fin volume decreases fast with the low values of $B i$ and decreases more slowly in the median values. It seems from this change that fins with bigger surface areas are needed for small $B i$ values. 
Table 1: Convergence test of the dimensionless tip temperature for different $m$ and $\beta$ values $(\psi=0.2, \lambda=3.0)$.

\begin{tabular}{|c|c|c|c|c|c|c|c|c|c|c|}
\hline & \multicolumn{2}{|c|}{$\mathrm{m}=0$} & \multicolumn{2}{|c|}{$\mathrm{m}=1 / 4$} & \multicolumn{2}{|c|}{$\mathrm{m}=1 / 3$} & \multicolumn{2}{|c|}{$\mathrm{m}=2$} & \multicolumn{2}{|c|}{$\mathrm{m}=3$} \\
\hline $\mathrm{M}$ & $\beta=-0.2$ & $\beta=0.2$ & $\beta=-0.2$ & $\beta=0.2$ & $\beta=-0.2$ & $\beta=0.2$ & $\beta=-0.2$ & $\beta=0.2$ & $\beta=-0.2$ & $\beta=0.2$ \\
\hline 10 & 0.569034 & 0.569034 & 0.597029 & 0.670907 & 0.670907 & 0.677053 & 0.677053 & 0.756591 & 0.743894 & 0.784240 \\
\hline 20 & 0.569094 & 0.569094 & 0.597059 & 0.671010 & 0.671010 & 0.677146 & 0.677146 & 0.756590 & 0.743812 & 0.784215 \\
\hline 30 & 0.569105 & 0.569105 & 0.597064 & 0.671029 & 0.671029 & 0.677164 & 0.677164 & 0.756590 & 0.743797 & 0.784210 \\
\hline 40 & 0.569109 & 0.569109 & 0.597066 & 0.671036 & 0.671036 & 0.677170 & 0.677170 & 0.756590 & 0.743791 & 0.784208 \\
\hline 50 & 0.569110 & 0.569110 & 0.597067 & 0.671039 & 0.671039 & 0.677173 & 0.677173 & 0.756590 & 0.743789 & 0.784207 \\
\hline 60 & 0.569111 & 0.569111 & 0.597067 & 0.671041 & 0.671041 & 0.677175 & 0.677175 & 0.756590 & 0.743788 & 0.784207 \\
\hline 70 & 0.569112 & 0.569112 & 0.597068 & 0.671042 & 0.671042 & 0.677176 & 0.677176 & 0.756590 & 0.743787 & 0.784207 \\
\hline 80 & 0.569112 & 0.569112 & 0.597068 & 0.671043 & 0.671043 & 0.677176 & 0.677176 & 0.756590 & 0.743786 & 0.784207 \\
\hline 90 & 0.569112 & 0.569112 & 0.597068 & 0.671043 & 0.671043 & 0.677177 & 0.677177 & 0.756590 & 0.743786 & 0.784207 \\
\hline 100 & 0.569112 & 0.569112 & 0.597068 & 0.671043 & 0.671043 & 0.677177 & 0.677177 & 0.756590 & 0.743785 & 0.784206 \\
\hline
\end{tabular}

Table 2: Comparison of the present solution and the exact solution for a linear case $(m=0, \beta=0, \lambda=2.0)$.

\begin{tabular}{|c|c|c|c|c|c|c|}
\hline \multirow[b]{2}{*}{$\mathrm{R}$} & \multicolumn{2}{|c|}{$\psi=0.05$} & \multicolumn{2}{|c|}{$\psi=0.10$} & \multicolumn{2}{|c|}{$\psi=0.20$} \\
\hline & Exact & VPM & Exact & VPM & Exact & VPM \\
\hline 0.0 & 1.0000000 & 1.0000000 & 1.0000000 & 1.0000000 & 1.0000000 & 1.0000000 \\
\hline 0.1 & 0.9932582 & 0.9932582 & 0.9868281 & 0.9868280 & 0.9748124 & 0.9748124 \\
\hline 0.3 & 0.9828285 & 0.9828284 & 0.9664919 & 0.9664918 & 0.9360806 & 0.9360805 \\
\hline 0.4 & 0.9789039 & 0.9789038 & 0.9588537 & 0.9588535 & 0.9215861 & 0.9215860 \\
\hline 0.5 & 0.9757229 & 0.9757228 & 0.9526689 & 0.9526687 & 0.9098727 & 0.9098724 \\
\hline 0.6 & 0.9732197 & 0.9732195 & 0.9478057 & 0.9478055 & 0.9006774 & 0.9006771 \\
\hline 0.7 & 0.9713403 & 0.9713401 & 0.9441569 & 0.9441566 & 0.8937874 & 0.8937871 \\
\hline 0.8 & 0.9700402 & 0.9700400 & 0.9416342 & 0.9416339 & 0.8890286 & 0.8890282 \\
\hline 0.9 & 0.9692825 & 0.9692823 & 0.9401645 & 0.9401641 & 0.8862579 & 0.8862575 \\
\hline 1.0 & 0.9690361 & 0.9690359 & 0.9396864 & 0.9396860 & 0.8853571 & 0.8853565 \\
\hline
\end{tabular}

Figure 4 shows that the maximum heat transfer rate for a given fin volume increases with the increased $B i$ number. While this increase is exponential for small $B i$ values, it becomes approximately linear when the $B i$ number gets bigger. Data in Figure 4 are for $(m ; \beta)=(2.0 ;-0.2)$ parameter values. To obtain more extensive results, data that are necessary to draw similar graphs for all values that $\beta$ and $m$ parameters can take properly to the problem of physics must be obtained.

For different values of the data parameters $(m=0,1 / 4,1 / 3,2.0$, $3.0)$ and $(\beta-0.2,-0.1,0.0,0.1,0.2)$ are obtained as a function of fin volume and Biot number and expressed with two identical correlation equations in the intervals of the independent variables appropriate to the physic problem $(0.0005 \leq B i \leq 0.2)$ and $(0.4 \leq v \leq 2.0)$.

$$
\lambda_{\text {opt }}, \dot{q}_{\text {max }}=\frac{a+b \ln (v)+c \ln (B i)+d[\ln (B i)]^{2}}{1+e \ln (v)+f[\ln (v)]^{2}+g \ln (B i)}
$$

Determination coefficients of 50 correlation equations with corresponding coefficients given in Table 3 , each one representing different parameters are $R^{2}>0.998$. The surfaces showing the optimum radii ratio and the surfaces showing the maximum variation of heat transfer rate for $(m ; \beta)=(2.0 ;-0.2)$ are shown in Figure 5 and Figure 6 . It is clear that these equations will provide great convenience to the designer in the optimum design of annular fins having various thermal parameters.

\section{Conclusions}

In this study, the optimum design of rectangular profile annular fins with thermal parameters changing with temperature was conducted. Temperature distribution inside the fin required to perform the optimization calculation was obtained by solving the nonlinear fin equation with the variation of parameters method. Optimum geometry of the fin, thermal conductivity parameter defining the variation of the conductivity with the temperature, fin parameter describing the fin geometry and thermal properties of fin were obtained in terms of exponential coefficient representing the heat transfer mode in the medium where the fin works and fin volume. These results are presented as correlation equations the designer can easily use.

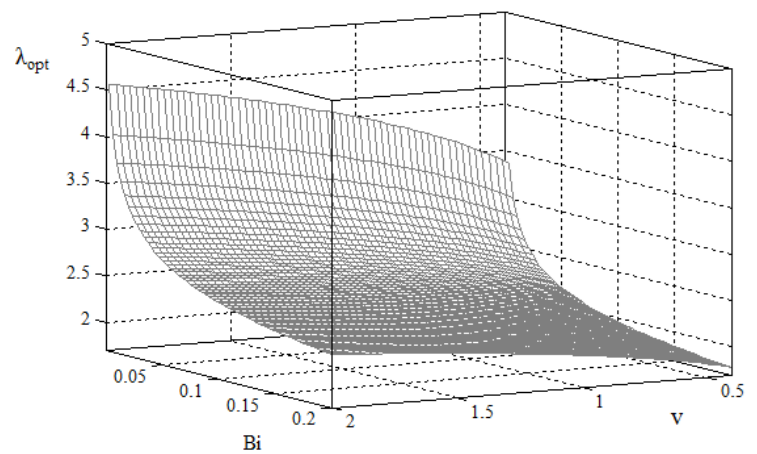

Figure 5: The optimum dimensionless radii ratio as a function of $v$ and $B i(m=2.0, \beta=-0.2)$.

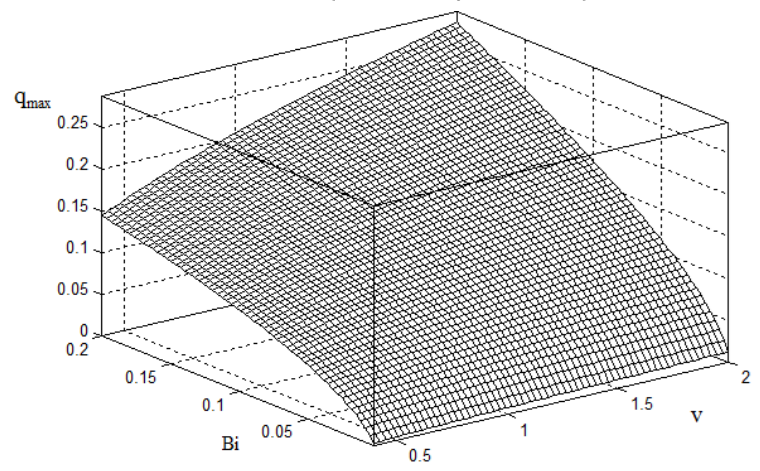

Figure 6: The maximum dimensionless heat transfer rate as a function of $v$ and $B i(m=2.0, \beta=-0.2)$. 
Table 3: Coefficients of Eq. (24) for optimum radii ratio and dimensionless heat transfer rate.

\begin{tabular}{|c|c|c|c|c|c|c|c|c|c|c|c|}
\hline & \multicolumn{3}{|c|}{$\mathrm{m}=0$} & \multicolumn{2}{|c|}{$\mathrm{m}=1 / 4$} & \multicolumn{2}{|c|}{$\mathrm{m}=1 / 3$} & \multicolumn{2}{|c|}{$m=2$} & \multicolumn{2}{|c|}{$m=3$} \\
\hline & & $\lambda_{\text {opt }}$ & $\mathrm{q}_{\max }$ & $\lambda_{\text {opt }}$ & $q_{\max }$ & $\lambda_{\text {opt }}$ & $\mathrm{q}_{\max }$ & $\lambda_{\text {opt }}$ & $\mathrm{q}_{\max }$ & $\lambda_{\text {opt }}$ & $\mathrm{q}_{\max }$ \\
\hline \multirow{8}{*}{$\begin{array}{l}\text { o } \\
0 \\
11 \\
\text { II } \\
0\end{array}$} & $\mathrm{a}$ & 1.827635094 & 0.835418425 & 1.804610562 & 0.785116666 & 1.796727502 & 0.770722023 & 1.681322846 & 0.602338526 & 1.635795975 & 0.549394765 \\
\hline & b & 0.041572907 & 0.028365066 & 0.034964069 & 0.026565105 & 0.034231305 & 0.026049711 & 0.011256411 & 0.020043961 & 0.004020831 & 0.018163082 \\
\hline & c & -0.108350350 & 0.217504026 & 0.102753280 & 0.204571067 & 0.101026960 & 0.200873096 & 0.080504550 & 0.157499141 & 0.072919460 & 0.143835315 \\
\hline & d & 0.026567943 & 0.015142211 & 0.026496379 & 0.014249453 & 0.026281994 & 0.013994428 & 0.023730746 & 0.010996030 & 0.022394601 & 0.010050146 \\
\hline & $e$ & -0.129071400 & & & & & - & - & & & \\
\hline & & $-0.1290 / 1400$ & 0.645228560 & 0.130322700 & 0.645287620 & 0.130201770 & 0.645277610 & 0.132330290 & 0.645771320 & 0.132426990 & 0.646031610 \\
\hline & $\mathrm{f}$ & 0.007508585 & 0.075636118 & 0.007722800 & 0.075286046 & 0.007402440 & 0.075168808 & 0.007611595 & 0.073937777 & 0.007479843 & 0.073536332 \\
\hline & $\mathrm{g}$ & 0.051734828 & 0.499397510 & 0.051317077 & 0.502709670 & 0.051411173 & $0.503652280^{-}$ & 0.051291907 & 0.517423170 & 0.051601817 & 0.522679190 \\
\hline \multirow{7}{*}{$\begin{array}{l}-1 \\
0 \\
11 \\
0 \\
0\end{array}$} & $\mathrm{a}$ & 1.842977808 & 0.767011373 & 1.819594832 & 0.721593331 & 1.812098785 & 0.708674567 & 1.697833931 & 0.555435566 & 1.653240702 & $\begin{array}{l}0.506978606 \\
0.016807757\end{array}$ \\
\hline & b & 043404217 & 0.026098363 & 0.038412348 & 0.024469951 & 0.035158335 & 0.024010140 & 0.014769640 & 0.018532199 & 0.007845215 & 0.016807757 \\
\hline & c & -0.111062810 & 0.199604969 & 0.106007800 & 0.187933213 & 0.104383990 & 0.184606115 & 0.084329010 & 0.145161755 & 0.076215450 & 0.132662669 \\
\hline & d & 0.026969699 & 0.013892108 & 0.026574109 & 0.013086660 & 0.026683046 & 0.012856617 & 0.024125065 & 0.010131408 & 0.022774207 & 0.009266490 \\
\hline & $\mathrm{e}$ & -0.129183140 & 0.645175580 & 0.129753650 & 0.645230550 & 0.130516440 & 0.645290760 & 0.132168730 & 0.645668490 & 0.132018200 & 0.64590 \\
\hline & $\mathrm{f}$ & 0.007562647 & 0.075804389 & 0.007600580 & 0.075457503 & 0.007879758 & 0.075410942 & 0.007579726 & 0.074097368 & 0.007459691 & 0.073685692 \\
\hline & $\mathrm{g}$ & 0.051671473 & 0.497628170 & 0.051594649 & 0.500878360 & 0.051314174 & 0.501979500 & 0.051235598 & 0.515356280 & 0.051680910 & 0.520544020 \\
\hline \multirow{7}{*}{$\begin{array}{l}0 \\
0 \\
11 \\
\infty\end{array}$} & $\mathrm{a}$ & 1.857655017 & 711075312 & 1.832506441 & 0.669564588 & 1.829963025 & 0.657669560 & 1.715532578 & 0.516782061 & 1.669603178 & 0.471962620 \\
\hline & c & -0.113557430 & 0.184972384 & 0.109737680 & 0.174309292 & 0.106779080 & 0.171252345 & 0.086622440 & 0.134998005 & 0.079368740 & 0.123451219 \\
\hline & d & 0.027286154 & 0.012870268 & 0.026768397 & 0.012134631 & 0.027683749 & 0.011923660 & 0.024436772 & 0.009419280 & 0.023234391 & 0.008621109 \\
\hline & 0 & & & & - & - & - & - & - & & - \\
\hline & $\mathrm{e}$ & -0.129177090 & 0.645135270 & 0.129633450 & 0.645182670 & 0.131964510 & 0.64520 & 4750 & 0.645584280 & 0.132056490 & 0.645786150 \\
\hline & $\mathrm{f}$ & 0.007639190 & 0.075968045 & 0.007521793 & 0.075621889 & 0.008129221 & 0.075520703 & 0.007557331 & 0.074248106 & 0.007390305 & 0.073835234 \\
\hline & $\mathrm{g}$ & 0.051710741 & 0.495985610 & 0.051653663 & 0.499179830 & 0.050517104 & 0.500142040 & 0.051457468 & 0.513449450 & 0.051571500 & 0.518515900 \\
\hline \multirow{7}{*}{$\begin{array}{l}\overrightarrow{0} \\
\text { "1 } \\
\infty\end{array}$} & $\mathrm{a}$ & 72307768 & 64366062 & 1.847308464 & & 1.841287170 & & 1.728816332 & & 1.686404360 & 0.442515141 \\
\hline & b & 0.048087420 & 0.022687837 & 0.046208643 & 0.021038146 & 0.043032730 & 0.020915289 & 0.022558073 & 0.016230980 & 0.013645620 & 0.014740377 \\
\hline & c & -0.115768170 & 0.172755801 & 0.112105100 & 0.162483773 & 0550 & 0.160094491 & 0.090 & 0.126458238 & 0.081 & 0.115690273 \\
\hline & d & 0.027721184 & 0.012017219 & 0.027008602 & 0.011309016 & 0.026932149 & 0.011143914 & 0.024524816 & 0.008821007 & 0.023710025 & 0.008076328 \\
\hline & e & -0.129051600 & & 3970 & & & & & & & \\
\hline & $\mathrm{f}$ & 0.007697502 & 0.076128160 & 0.007624364 & 0.067846987 & 0.007530246 & 0.075679014 & 0.007474986 & 0.074396283 & 0.007600387 & 0.073967198 \\
\hline & g & 0.051630910 & $\overline{0} .494456660$ & 0.051810610 & 0.494471230 & 0.051738359 & 0.498549160 & 0.051643523 & 0.511707200 & 0.051497415 & 0.516820270 \\
\hline \multirow{6}{*}{$\begin{array}{l}\text { Na } \\
\text { II } \\
\varrho\end{array}$} & $\mathrm{a}$ & 1.889306078 & 0.624739659 & 1.860350863 & 0.589078957 & 1.850669876 & 0.578821485 & 1.745194852 & 0.456531643 & 1.700004498 & 0.417264391 \\
\hline & b & 0.049450048 & 0.021382576 & 0.048706336 & 0.020087820 & 0.049613784 & 0.019716956 & 0.024269756 & 0.015330041 & 0.017349727 & 0.013932551 \\
\hline & c & -0.114795290 & 0.162385620 & 0.114759780 & 0.153239923 & 0.114654650 & 0.150606150 & 0.092904380 & 0.119161688 & 0.085101300 & 0.109042625 \\
\hline & $\mathrm{e}$ & -0.125150100 & 0.645083280 & 127927920 & 0.645134270 & 0.127151020 & 0.645144930 & 0.131259870 & 0.645450170 & 0.131147050 & 0.645553140 \\
\hline & $\mathrm{f}$ & 0.008129253 & 0.076251988 & 0.007398206 & 0.075935084 & 0.007337890 & 0.075835365 & 0.007588955 & 0.074534424 & 0.007463609 & 0.074080338 \\
\hline & $\mathrm{g}$ & 0.052261325 & 0.493158700 & 0.052476560 & 0.496190160 & 0.052720334 & 0.497098960 & 0.051318825 & 0.510084680 & 0.051677125 & 0.515076930 \\
\hline
\end{tabular}

\section{References}

[1] Kraus AD, Aziz A, Welty J. Extended Surface Heat Transfer. New York, USA, John Wiley \& Sons Inc., 2001.

[2] Laor K, Kalman H. "Performance and optimum dimensions of different cooling fins with a temperature-dependent heat transfer coefficient". International Journal of Heat and Mass Transfer, 39, 1993-2003, 1996.

[3] Aksoy IG. "Thermal analysis of annular fins with temperature-dependent thermal properties". Applied Mathematics and Mechanics English Edition, 34, 13491360, 2013.

[4] Chang MH. "Decomposition solution for fins with temperature dependent surface heat flux". International Journal of Heat and Mass Transfer, 48, 1819-1824, 2005.

[5] Kim S, Huang CH. "A series solution of the non-linear fin problem with temperature dependent thermal conductivity and heat transfer coefficient". Journal of Physics D: Applied Physics, 40, 2979-2987, 2007.

[6] Khani F, Raji MA, Nejad HH. "Analytical solutions and efficiency of the nonlinear fin problem with temperaturedependent thermal conductivity and heat transfer coefficient". Communication in Nonlinear Science and Numerical Simulation, 14, 3327-3338, 2009.
[7] Mosayebidorcheh S, Hatami M, Mosayebidorcheh T, Ganji D.D. "Optimization analysis of convective-radiative longitudinal fins with temperature-dependent properties and different section shapes and materials". Energy Conversion and Management, 106, 1286-1294, 2015.

[8] Arslanturk C. "Correlation equations for optimum design of annular fins with the temperature dependent thermal conductivity". Heat and Mass Transfer, 45, 519-525, 2009.

[9] Kundu B, Bhanja D. "Performance and optimization analysis of a constructal T-shaped fin subject to variable thermal conductivity and convective heat transfer coefficient International Journal of Heat and Mass Transfer, 53, 254-267, 2010.

[10] Bouaziz MN, Aziz A. "Simple and accurate solution for convective-radiative fin with temperature dependent thermal conductivity using double optimal linearization". Energy Conversion and Management, 51, 2776-2782, 2010.

[11] Kundu B. "Analytic method for thermal performance and optimization of an absorber plate fin having variable thermal conductivity and overall loss coefficient". Applied Energy, 87, 2243-2255, 2010. 
[12] Khani F, Aziz A. "Thermal analysis of a longitudinal trapezoidal fin with temperature-dependent thermal conductivity and heat transfer coefficient". Communication in Nonlinear Science and Numerical Simulation, 15, 590-601, 2010.

[13] Aziz A, Khani F. "Convection-radiation from a continuously moving fin of variable thermal conductivity". Journal of Franklin Institute, 348, 640-651, 2011.

[14] Torabi M, Aziz A. "Thermal performance and efficiency of convective-radiative T-Shaped fin with temperature dependent thermal conductivity, heat transfer coefficient and surface emissivity". International Communication in Heat and Mass Transfer, 39, 1018-1029, 2012.

[15] Mosayebidorcheh S, Farzinpoor M, Ganji DD. "Transient thermal analysis of longitudinal fins with internal heat generation considering temperature-dependent properties and different fin profiles". Energy Conversion and Management, 86, 365-370, 2014.

[16] M Moradi A, Hayat T, Alsaedi A. "Convection-radiation thermal analysis of triangular porous fins with temperature-dependent thermal conductivity by DTM". Energy Conversion and Management, 77, 70-77, 2014.
[17] Cengel YA, Palm WJ. Differential Equations for Engineers and Scientists, New York, USA, McGraw Hill, 2012.

[18] Mohyud-Din ST, Noor MA, Waheed A. "Variation of parameters method for initial and boundary value problems". World Applied Sciences Journal, 11, 622-639, 2010.

[19] Rahmatullah, Mohyud-Din ST. "Variation of parameters method for nonlinear diffusion equations". International Journal Modern Applied Physics, 3, 48-56, 2013.

[20] Moore TJ. Application of Variation of Parameters to Solve Nonlinear Multimode Heat Transfer Problems. PhD Dissertation; Brigham Young University, USA, 2014.

[21] Moore TJ, Jones MR. "Analysis of the conduction-radiation problem in absorbing, emitting, non-gray planar media using an exact method International Journal of Heat and Mass Transfer, 73, 804-809, 2014.

[22] Bergman TL, Lavine AS, Incropera, FP, DeWitt DP. Fundamentals of Heat and Mass Transfer. $7^{\text {th }}$ ed. New Jersey, USA, John Wiley and Sons, 2011. 